\title{
NUMERICAL MODEL OF SiC PARTICLE INTERACTION WITH SOLIDIFICATION FRONT IN AZ91/( $\left.\mathrm{SiC}_{\mathrm{p}}\right)$ COMPOSITE
}

\begin{abstract}
Presented work focused on the movement of $\mathrm{SiC}$ particles in the vicinity of the solidification front in $\mathrm{AZ} 91 /(\mathrm{SiC})_{\mathrm{P}}$ composite. Authors describe the mathematical model that governs this phenomenon. On the base of following numerical model own computer program was prepared. The behavior of a particle moving parallel to the solidification front was analyzed. Three variants of local velocity gradient of liquid metallic phase were analyzed for a particle of radius 10,50 and $100 \mu \mathrm{m}$. At a bigger velocity gradient the $\mathrm{SiC}$ particle was observed to go down quicker and to move towards the solidification front. This effect was stronger for SiC particles, which had a bigger radius, i.e. 100 and $50 \mu \mathrm{m}$.
\end{abstract}

Keywords: $\left.\mathrm{AZ91/(} \mathrm{SiC}_{\mathrm{p}}\right)$ composite, solidification front, modeling

\section{Introduction}

During solidification of a composite, the moving solidification front may push away or attract particles in the liquid phase. In the latter case the nonmetallic phase can evenly distribute in the cast, otherwise the particles are clustering forming bigger groups, which either drop down or swim up to the surface. During directional solidification, when the front is flat, the particles which were pushed away from the front move inside the cast. If the solidification front has a dendritic character, the pushed phases gather in interdendritic areas, and as the solidification continues, they are closed in the space by dendrites boundaries. Whether the particles are pushed away or attracted by the front depends on physicochemical phenomena accompanying solidification, as well as the character of the front [1-8].

When the solidification front is vertical and moves horizontally, the particle cannot be clearly defined as not moving. In this case the movement of particles with respect to the front and the surrounding liquid phase has to be taken into account. A flat system of forces having impact on the particle consists of the following components:

- $\quad$ force relating to the difference of densities (gravity force) [1-7]:

$$
F_{g}=\frac{4}{3} \pi r^{3}\left(\rho_{m}-\rho_{p}\right) g
$$

$F_{g}$ - difference between buoyancy and weight $[\mathrm{N}]$,

$\rho_{m}-$ density of alloy $\left[\mathrm{kg} \mathrm{m}^{-3}\right]$,

$\rho_{p}-$ density of SiC particles $\left[\mathrm{kg} \mathrm{m}^{-3}\right]$, $g-$ acceleration of gravity $\left[\mathrm{m} \mathrm{s}^{-2}\right]$,

$r$ - radius $\mathrm{SiC}$ particles [m].

- viscous drag, which has an opposite direction to the particle velocity vector $V_{p}$, which is moving in the fluid [1,3,5-7, 9-11]:

$$
F_{d}=6 \pi \mu r V_{p} \theta
$$

where:

$F_{d}-$ viscous drag force $[\mathrm{N}]$

$\mu-$ coefficient of dynamic viscosity $\left[\mathrm{kg} \mathrm{m}^{-1} \mathrm{~s}^{-1}\right]$,

$V_{p}$ - velocity of particle vector against fluid, which value is later denoted $V_{c z}\left[\mathrm{~m} \mathrm{~s}^{-1}\right]$.

The value of coefficient $\theta$ depends on the distance from the front $h[\mathrm{~m}]$ and direction in which particles are mov ${ }^{\circ}$ g. For a particle moving parallel to the front $\theta=\ln (r / h)[1 / 1]$.

- force generated by a velocity gradient of fluid moving perpendicular to the surface of the front, i.e. Saffman force. This force is responsible for the drifting away of approaching of particles towards the front, depending on the direction of movement of the liquid phase and density difference of particle and liquid alloy $[1,3,5-7,9-11]$ :

$$
F_{s}=6,46 \mu r^{2} V_{c z} \sqrt{\frac{S}{v}}
$$

where:

$$
\begin{aligned}
F_{s} & - \text { Saffman force }[\mathrm{N}], \\
r & - \text { radius of precipitation particles }[\mathrm{m}], \\
v & - \text { kinematic viscosity }\left[\mathrm{m}^{2} \mathrm{~s}^{-1}\right]
\end{aligned}
$$


$S$ - value of fluid velocity local gradient $\left[\mathrm{s}^{-1}\right]$. In discussed case (fluid moving parallel to the solidification front surface) is equal to flow velocity differences between layers against distance between layers that tends to zero.

The interaction of particles with a front was analyzed for

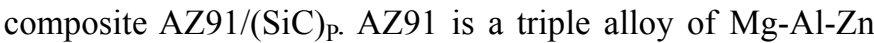
with $9 \% \mathrm{Al}$ and $1 \% \mathrm{Zn}$. An even distribution of particles of this phase in the casting is very important when producing composite

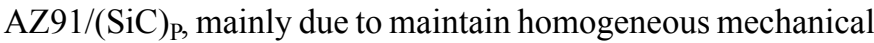
properties in whole casting volume $[12,13]$.

\section{Model}

This chapter describes a simplified model, which describe particle motion as a result of the interaction forces that acting on a particle, i.e. gravity, viscous drag and Saffman forces. The second Newton's law gives dependency that lead to equations which can be used for particles velocity, $\left(V_{x}, V_{y}\right)$, and location $\left(X_{x}, X_{y}\right)$ description. They are dependent on acceleration $\left(a_{x}, a_{y}\right)$ which depends of force that acts on the particle.

$$
a=\frac{F}{m} ; m=\frac{4}{3} \pi r^{3} \rho_{c z}
$$

The direction of $x$ axis and $y$ axis will be analyzed separately in the model:

$$
\left\{\begin{array} { l } 
{ \frac { d V _ { x } } { d t } = a _ { x } } \\
{ V _ { x } ( 0 ) = V _ { 0 _ { x } } }
\end{array} \quad \left\{\begin{array}{l}
\frac{d V_{y}}{d t}=a_{y} \\
V_{y}(0)=V_{0_{y}}
\end{array}\right.\right.
$$

$V_{x}, V_{y}-$ component of velocity vector along $x$ axis and $y$ axis,

$$
\left\{\begin{array} { l } 
{ \frac { d X _ { x } } { d t } = V _ { x } } \\
{ X _ { x } ( 0 ) = X _ { 0 _ { x } } }
\end{array} \quad \left\{\begin{array}{l}
\frac{d X_{y}}{d t}=V_{y} \\
X_{y}(0)=X_{0_{y}}
\end{array}\right.\right.
$$

$X_{x}, X_{y}$ - component of location vector along $x$ axis and $y$ axis, respectively.

Formulas 5 and 6 are being solved simultaneously. To solve them the forces that implies acceleration at each end every direction must be taken into account.

During its movement the particle, which moves against fluid of $V_{l}$ velocity, is exposed on the forces act that is shown in figure $1[1,8,11]$. The $F_{r}$ and $F_{d}$ forces impact on the acceleration are at different directions. To take them into account the coordinates system was introduce into the analyzed system with its origin connected to the particle initial position. During computations it was assumed that local gradient of fluid velocity, $S$, is constant.

The computations were divided into two stages. At the first stage positive value part of acceleration connected to resultant force, $F_{r}$, is added. At the second stage negative value part of acceleration connected to drag force, $F_{d}$, is added.

Resultant force, $F_{r}$, direction is dependent on length of $F_{S}$ and $F_{g}$ forces. It was assumed that $F_{S}$ and $F_{g}$ forces directions are parallel respectively to $x$ and $y$ axis (this assumption is pos-

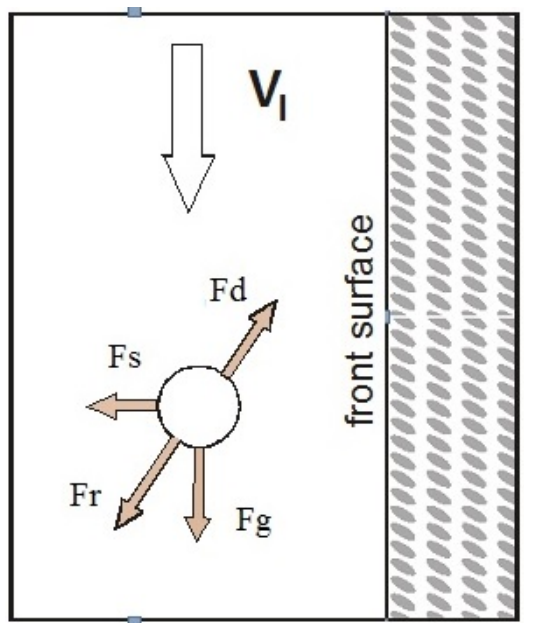

Fig. 1. Schematic showing forces that acting on a particle, and fluid moving velocity vector, $V_{l}$

sible as the Saffman force is perpendicular to the solidification front and the gravity force acts parallel to the front) (Fig. 1). The drag force, $F_{d}$, has the same direction as actual particle velocity vector, $V_{p}$.

Basing on the balance of forces (Fig. 1), the resultant force value $F_{r}$ was calculated:

$$
\left|F_{r}\right|=\sqrt{\left|F_{g}\right|^{2}+\left|F_{S}^{2}\right|}
$$

Under given assumptions $F_{S}$ and $F_{g}$ forces are components of resultant force. Resultant force as vector is used for acceleration components $\left(a_{x}, a_{y}\right)$ of the particle.

Analogously the drag force is taken into account. Its direction is the same as the as the actual velocity vector, $V_{p}$, but it sense is opposite. Its components are projected on $x$ and $y$ axis, and then used for the negative acceleration components value, which updates the acceleration vector.

For the initial state, the velocity of particles in the initial position along $x$ axis was assumed to be $V_{x 0}$. The process was divided in several time intervals of constant $\Delta t$ distance. With the ongoing process, the velocity was changing and after $f+1$ time steps value of velocity along $x$ axis was equal to $V_{x}^{f+1}$. Knowing the coordinates of the current position, the successive position can be defined.

Using the explicit Euler scheme for a certain step $t^{f}$ : following algorithm is obtain:

$$
\begin{aligned}
& \left\{\begin{array}{l}
V_{x}{ }^{f+1}=V_{x}{ }^{f}+a_{x}{ }^{f} \Delta t \\
V_{y}{ }^{f+1}=V_{y}{ }^{f}+a_{y}{ }^{f} \Delta t
\end{array}\right. \\
& V_{c z}{ }^{n}=\sqrt{\left(V_{x}{ }^{n}\right)^{2}+\left(V_{y}{ }^{n}\right)^{2}}
\end{aligned}
$$

The acceleration vector components values necessary to solve equations 7 were calculated basing on the balance of forces that acts on the particle at each and every discrete time step separately along $x$ axis and $y$ axis. 
For the sake of tracing the movement of particles: from the point $\left(X_{x}^{f}, X_{y}^{f}\right)$ to $\left(X_{x}^{f+1}, X_{y}^{f+1}\right)$ following relation was used:

$$
\left\{\begin{array}{l}
X_{x}^{f+1}=X_{x}^{f}+\Delta t V_{x}^{f} \\
X_{y}^{f+1}=X_{y}^{f}+\Delta t V_{y}^{f}
\end{array}\right.
$$

\section{Results of calculations and discussion}

The calculations were performed with a computer program worked out on the basis of presented mathematical and numerical model. The following parameters were assumed for AZ91 alloy and $\mathrm{SiC}$ phase: density of $\mathrm{AZ91}=1713.83\left[\mathrm{~kg} \mathrm{~m}^{-3}\right][14,15]$, density of particles $=3210\left[\mathrm{~kg} \mathrm{~m}^{-3}\right][14,15]$, coefficient of dynamic viscosity $0.00125\left[\mathrm{~kg} \mathrm{~m}^{-1} \mathrm{~s}^{-1}\right]$ [16], length of time step $1 \times 10^{-6}[\mathrm{~s}]$, end of calculation cycle $10[\mathrm{~s}]$, radius of particles $=10,50$ and $100 \mu \mathrm{m}$, local velocity gradient $=0.0001 ; 0.00001$;
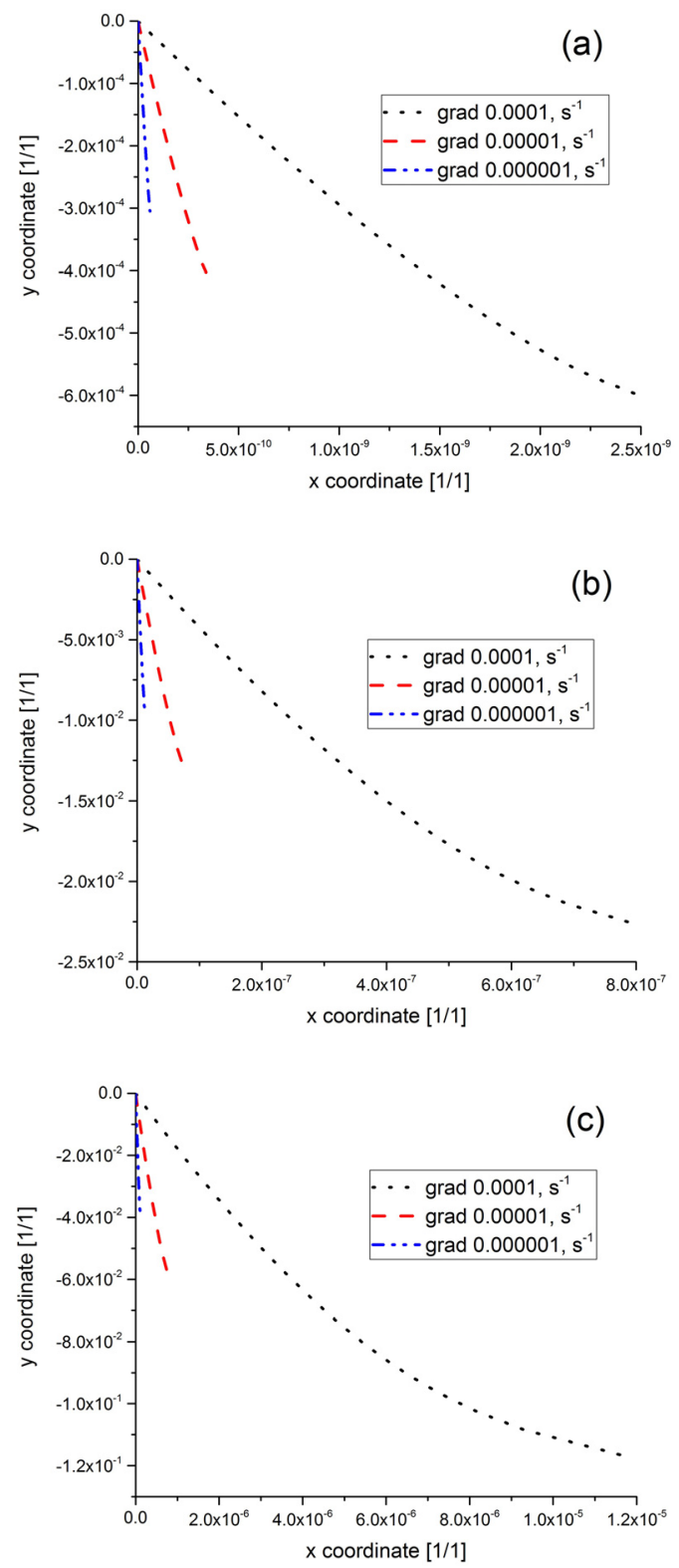

Fig. 3. The results of calculations for particles of different radius: (a) 10, (b) 50 , (c) $100 \mu \mathrm{m}$ $\left.0.000001 \mathrm{~s}^{-1}\right]$. The analyzed case involved $\mathrm{SiC}$ particles moving parallel to the solidification front. The influence of local velocity gradient on the movement of particles of a given radius was analyzed. The results of calculations for particles of radius: 10 , 50, $100 \mu \mathrm{m}$ were presented in Fig. 3a-c for various gradients of fluid velocity. The trajectories of movement of particles of given radii and for given gradients of velocity were presented in Fig. 4a-c. The calculations were conducted and listed for cycles of constant length equal to $10 \mathrm{~s}$.
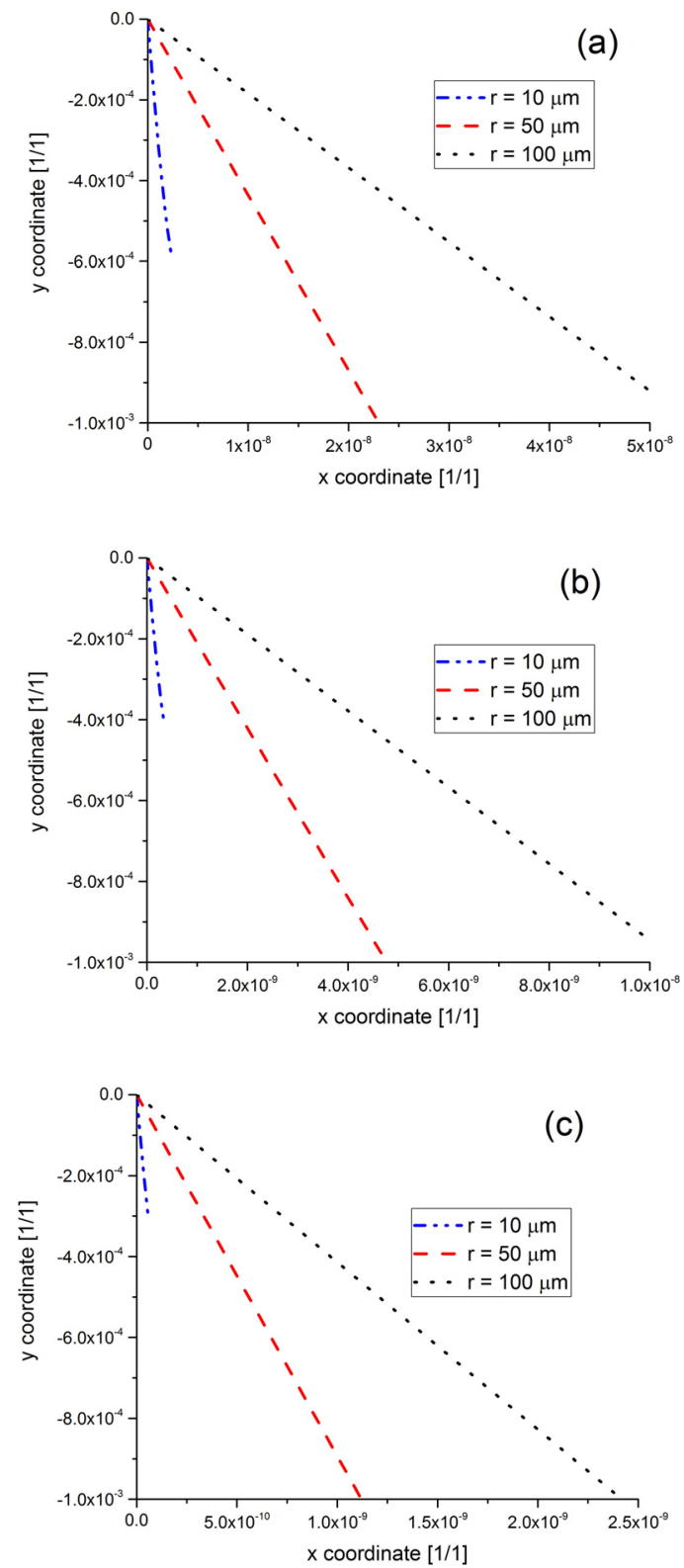

Fig. 4. Influence of local gradient of velocity on the trajectories of particles SiC: (a) $S=0.0001 \mathrm{~s}^{-1}$, (b) $S=0.00001 \mathrm{~s}^{-1}$, (c) $S=0.000001 \mathrm{~s}^{-1}$

The influence of the radius of the particles with constant and known velocity gradient was analyzed in the paper. The analysis of the plots reveals that the bigger is the radius of particle, the closer it is to the front, with the velocity gradient as a very important factor. The lower is the gradient, the more distant is the particle from the front. 
The value of local velocity gradient has a significant influence on the trajectory of the $\mathrm{SiC}$ particle. The bigger is the gradient, the closer is the particle to the front. The value of the velocity gradient was also observed to change the trajectory of the particle. At the initial stage, the $\mathrm{SiC}$ particle moved along the straight line; by changing its placement with respect to $y$ axis makes the trajectory slightly bend towards the front. The bigger is the velocity gradient, the more the particle accelerates, faster drops down and approaches the solidification front. By comparing the localization of particles with respect to $x$ axis an observation was made that particles of bigger radii occupy a position in a close proximity of the solidification front. The bigger is the radius of this phase, the more easily is maintained the trend.

\section{Conclusion}

Thermophysical parameters, radius of $\mathrm{SiC}$ particles and also gradient of liquid phase velocity determine the trajectory along which the particles are moving. A plot visualizing the movement of a particle was obtained for the analyzed variant and given parameters, i.e. local velocity gradient and size of particles. A particle moving along the front changes its trajectory and goes towards the front. This is connected with the decreasing distance between particles and the solidification front. The results presented in this paper can be used by persons dealing with composite casting. Further studies with the use of the discussed model can be conducted on other metallic-base composites. The mathematical model is also applicable to the analysis of movement of precipitations produced in the process of steel casting.

\section{Acknowledgements}

This work was sponsored by Ministry of Science as the statute work AGH UST - University of Science and Technology in Krakow (contract 11.11.170.318.14).

\section{REFERENCES}

[1] Q. Han, J. Hunt, ISIJ Int. 35, 693-699 (1995).

[2] D. M. Stefanescu, B.K. Dhindaw, S.A. Kacar, A. Moitra, Met. Trans. A 19A, 2847-2855 (1988).

[3] D. Shangguan, S. Ahuja, D.M. Stefanescu, Met. Trans. A 23A, 669-680 (1992).

[4] S. Kimura, Y. Nabeshima, K. Nakajima, S. Mizoguchi, Metal Trans. B 31 B, 1013-1021 (2000).

[5] B.K. Sen, B.K. Dhindaw, D.M. Stefanescu, A. Catalina, P.A. Curreri, J. Crystal Growth 173, 574-584 (1997).

[6] D. Kalisz, Termodynamiczna charakterystyka powstawania fazy niemetalicznej w ciekłej stali, Akapit Krakow (2013).

[7] D. Kalisz, Archives of Metallurgy and Materials 59, 2, 493-500 (2014).

[8] E. Fraś, E. Olejnik, Archives of Metallurgy and Materials 53, 3, 695-702 (2008)

[9] P.L. Żak, D. Kalisz, J. Lelito, M. Szucki, B. Gracz, J.S. Suchy, Metalurgija 54, 2, 357-360 (2015).

[10] M. Szucki, D. Kalisz, J. Lelito, P. L. Żak, J. S. Suchy, K W. Krajewski, Metalurgija 54, 2, 375-378 (2015).

[11] S. Mukherjee, D.M. Stefanescu, Metallurgical and Materials Transactions A 35 A, 613-621 (2004).

[12] J. Lelito, P.L. Żak, B. Gracz, M. Szucki, D. Kalisz, P. Malinowski, J. S. Suchy, Metalurgija 54, 1, 204-206 (2015).

[13] J. Lelito, Modelowanie krystalizacji kompozytu AZ91/SiC, Wydawnictwo Archives of Foundry Engineering, Katowice-Gliwice 2012.

[14] J. Lelito, P.L. Żak, A.A. Shirzadi, A.L. Greer, W.K. Krajewski, J.S. Suchy, K. Haberl, P. Schumacher, Acta Materialia 60, 6-7, 2950-2958 (2012).

[15] J. Lelito, P.L. Żak, J. Suchy, W.K. Krajewski, B. Gracz, M. Szucki, A.A. Shirzadi, Composites Part B: Engineering 43, 8, 3306-3309 (2012).

[16] Flow Science: Flow3D software database: https://www.flow3d. com/ 